\title{
Smart control strategy for PV and heat pump system utilizing thermal and electrical storage and forecast services
}

\author{
Emmanouil Psimopoulos ${ }^{1,2}$, Elena Bee ${ }^{3}$, Rasmus Luthander ${ }^{2}$, Chris Bales ${ }^{1}$ \\ 1 Energy Technology, Dalarna University, Borlänge, Sweden \\ 2 Department of Engineering Sciences, Uppsala University, Uppsala, Sweden
}

3 Department of Civil, Environmental and Mechanical Engineering - University of Trento, Trento, Italy

\begin{abstract}
In this study, a detailed model of a single-family house with exhaust air heat pump, PV system and energy hub developed in the simulation software TRNSYS 17 is used to evaluate energy management algorithms that utilize weather and electricity price forecasts. A system with independent PV and heat pump is used as a base case. The three smart and predictive control algorithms were developed with the scope to minimize annual cost of bought electricity by the use of the thermal storage of the building, the hot water tank and electrical storage. The results show reduction of the final energy of $26.4 \%$, increase of the self-consumption to $60 \%$ and decrease of the net annual cost for electricity of $15 \%$ when using the forecast services in combination with thermal and electrical storage compared to the base case.
\end{abstract}

Keywords: photovoltaics, heat pump, forecast services, thermal storage, electrical storage

\section{Nomenclature}

DHW Domestic hot water

FE Final energy

HP Heat pump

PV Photovoltaics

NCOE Annual cost of electricity

SC Self-consumption [\%]

SH Space heating

\section{Introduction}

Sophisticated control of HPs can provide the flexibility to match the onsite PV electricity production with the household load for space heating (SH) and domestic hot water (DHW). Batteries have the advantage of being able to store electricity for later use and are a suitable option for short term storage of PV electricity in buildings (Luthander et al., 2015), while thermal storage has also been studied in combination with heat pumps. For example, according to Fischer and Madani (2017), rule based approaches lead to cost reduction by 2 to $4 \%$. Salpakari and Lund (2016) studied the optimal cost control for PV systems with thermal and electrical energy storage based on the electricity price and Thygesen and Karlsson (2016) proposed a control strategy based on a perfect short-term weather forecast for a PV system with a heat pump and thermal and energy storage that showed low profitability. Strategies for improving PV self-consumption in residential buildings with energy storage and 
the various control approaches, including rule based and predictive control have been reviewed thoroughly by Luthander et al., (2015) and Fischer and Madani (2016) respectively. The majority of the studies that focus on PV are in combination with battery storage but heat pumps plus hot water storage have shown increasing interest in recent years (Binder et al., 2012; Hesaraki and Holmberg, 2013; Thygesen and Karlsson, 2014; Luthander et al., 2015; Hirvonen et al., 2016; Fischer et al. 2017). This study evaluates predictive control measures for systems with PV and heat pumps for a single-family house in Sweden. For the base case, a detailed model of a new singlefamily house with a grid-connected PV system, exhaust air heat pump and hot water storage is used. In this base case scenario, the heat pump is not controlled to increase the internal use of the PV electricity. The model is further developed to include electrical storage.

\subsection{Aim of study}

The objective of this study is to develop and evaluate algorithms that use forecasts of weather and electricity price on hourly basis in order to reduce the annual final energy and net cost of electricity. In a previous study, Psimopoulos et al. (2016) developed control algorithms to utilize more effectively the excess PV electricity production. The previous results have focused on energetic improvement such as to increase the self-consumption (SC) and to reduce the bought electricity from the grid, namely final energy (FE). In the follow-up study presented here, a simplified economical evaluation of the running cost and revenue is used as for generating the net cost of electricity that is used for the optimization. In Sweden, it is already possible for house owners and PV micro producers to have an electricity tariff coupled with the Nord Pool spot market price, with tariffs on hourly basis (Sommerfeldt and Madani, 2015). What is new in this work is the proposed operational control strategies in addition to the short time-step weather data and load profiles for both domestic hot water (DHW) and electricity demand. Another difference to other studies is that the exhaust air heat pump, very common in Sweden, cannot supply the full heating rate required and thus control of the electrical auxiliary heater is important and also modelled in detailed in this study.

The scope of the study is for a modern single family house with exhaust air heat pump located in Sweden. The stochastical load patterns are based on monitoring data for single family houses described in Widén et al., (2012, 2009). All these are implemented in the simulation software TRNSYS 17, where the components in the model are parameterized to match the specifications of existing products on the market. Net cost of energy is considered in the analysis based on spot market price and no feed-in subsidies. A full economic evaluation including investment cost is out of scope of this paper, rather the focus is on impact of advanced control algorithms assuming the system already exists.

\section{Methodology}

\subsection{Boundary conditions for the system}

The system with heat pump supplies a typical Swedish single family house (SFH) with a gabled roof of one floor that has an overall $\mathrm{U}$-value of $0.2 \mathrm{~W} \mathrm{~m}^{-2} \mathrm{~K}^{-1}$ and $143 \mathrm{~m}^{2}$ heated floor area. A detailed model of the house with six zones, developed in the simulation software TRNSYS, is described in detail and validated by Persson and Heier (2010). TRNSYS' type 56 is used for the house model. Three zones (rooms) have a set temperature of $20^{\circ} \mathrm{C}$, while two zones have $21^{\circ} \mathrm{C}$ and one zone has $22^{\circ} \mathrm{C}$ as set temperatures (Persson and Heier, 2010). The location of the house is Norrköping, Sweden $\left(58.6^{\circ} \mathrm{N}, 16^{\circ} 2 \mathrm{E}\right)$. Measured high-resolution (one minute) meteorological data by the Swedish Meteorological and Hydrological Institute (SMHI) from the year 2011 in Norrköping is used in the simulations. The weather data is used both for calculation of the PV electricity production and for calculations of energy gains and losses in the house. Fresh water temperature, which affects the heating demand, is dependent on the time of the year and modelled using a function described by Heimrath and Haller (2007). Two adults and two children are living in the house, and the internal heat energy gain, assumed to be the same as the electricity demand for appliances, is calculated using a Markov-chain model for occupancy and energy use as described in Widén et al. (2009). The DHW demand is derived from the MacSheep project and adjusted for this study (Bales et al., 2015), see Table 1. Domestic electricity and DHW loads have a 2 minute resolution over the period of one year. 
Tab. 1: SH, DHW and appliance data

\begin{tabular}{cc}
\hline $\mathbf{2 9 7 9}$ & Discharge energy $\left[\mathbf{k W h}\right.$ year $\left.{ }^{-1}\right]$ \\
$\mathbf{7 0 . 9}$ & Discharge DHW volume $\left[\mathrm{m}^{3}\right.$ year $\left.^{-1}\right]$ \\
$\mathbf{4 5}$ & Discharge DHW temperature $\left[{ }^{\circ} \mathrm{C}\right]$ \\
$\mathbf{1 9 4 . 2}$ & Daily Average DHW draw-off $[\mathrm{kg}]$ \\
$\mathbf{2 . 4 4 - 9 7 2 . 2}$ & DHW flow $\left[\mathrm{kg} \mathrm{h}^{-1}\right]$ \\
$\mathbf{3 4 3 7}$ & Electricity for appliances $\left[\mathrm{kWh} \mathrm{year}^{-1}\right]$ \\
$\mathbf{1 4 0 4 6}$ & Space heating load $\left[\mathrm{kWh}^{-1}\right.$ year $\left.{ }^{-1}\right]$ \\
$\mathbf{5 6 5 0}$ & Max load for appliances $[\mathrm{W}]$ \\
\hline
\end{tabular}

\subsection{Hot water storage tank, heat pump and auxiliary heater}

A variable speed, exhaust air HP delivers heat both for SH and DHW but cannot supply them both at the same time. The HP model is based on the performance map of the HP, with heat capacity and power input as dependent variables together with inlet air temperature, inlet air flow rate and compressor speed as independent variables. A hot water storage tank of 180 litres is used for DHW whereas the SH is supplied by the HP through a buffer store of 25 litres. The HP is activated according to a heating curve and compensatory control algorithm dependent on the SH supply temperature. An electric auxiliary heater is activated when the thermal power provided by the heat pump is insufficient to meet thermal power need. The auxiliary heater is turned off during the predefined summer period. Table 2 shows the values used in this study for the DHW storage, heat pump and auxiliary heater. The models for the HP, DHW storage and internal control algorithms are based on common commercial products on the market. The performance characteristics as well as detailed control algorithm are based on those for a commercial integrated product with heat pump and DHW store as one 60x60 cm appliance unit.

Tab. 2 : Specifications of hot water storage tank, exhaust air heat pump and auxiliary heater

\begin{tabular}{cc}
\hline Preference & Quantity \\
\hline DHW storage tank capacity [litre] & 180 \\
Electric compressor power $[\mathrm{kW}]$ & $0.27-2.05$ \\
Thermal power of HP $[\mathrm{kW}]$ & $1.14-4.99$ \\
Heat pump COP & $2.4-4.7$ \\
Electric auxiliary heater $[\mathrm{kW}]$ & $0.5-6.5$ \\
\hline
\end{tabular}

\subsection{Battery storage and PV system}

Three PV system sizes and three battery storage sizes are used to study the impact on the energetic and economic performance in terms of self-consumption, and final energy, with details described in Table 3 . The tilt angle is defined by the roof of the building whereas the azimuth angle is chosen to optimize the yearly PV electricity production. The PV panels, inverter and lithium-ion batteries are modelled according to the specification of products available on the market. 
Tab. 3: Specifications of the PV system and battery storage

\begin{tabular}{cc}
\hline Preference & Quantity/name \\
\hline Capacity PV $[\mathrm{kW}]$ & $3.12,5.7,9.36$ \\
Inverter efficiency [\%] & 97.7 \\
PV tilt $\left[^{\circ}\right]$ & 27 \\
PV azimuth $\left[{ }^{\circ}\right]$ & 0 \\
Capacity battery $[\mathrm{kWh}]$ & $3.6,7.2,10.8$ \\
Round-trip battery losses $[\%]$ & $10 \%$
\end{tabular}

\subsection{Electricity tariff}

Figure 1 shows the annual variation of the Nord Pool spot market price for year 2011 in central Sweden. The purchased electricity price that is used for this study includes the following: the spot market price, the grid fee, the electricity certificate and the value added tax. For the case of the feed-in electricity to the grid, only the spot market price and the electricity certificate without the current tax reduction subsidy available in Sweden are considered. For the end user, this results in a mean value of $0.08 € / \mathrm{kWh}$ of various fees is added to the hourly spot market price for the purchased electricity and $0.015 € / \mathrm{kWh}$ is added to the hourly spot market price for the excess electricity fed to the grid. The added values are derived from 2011 market data (Nord Pool, 2016).

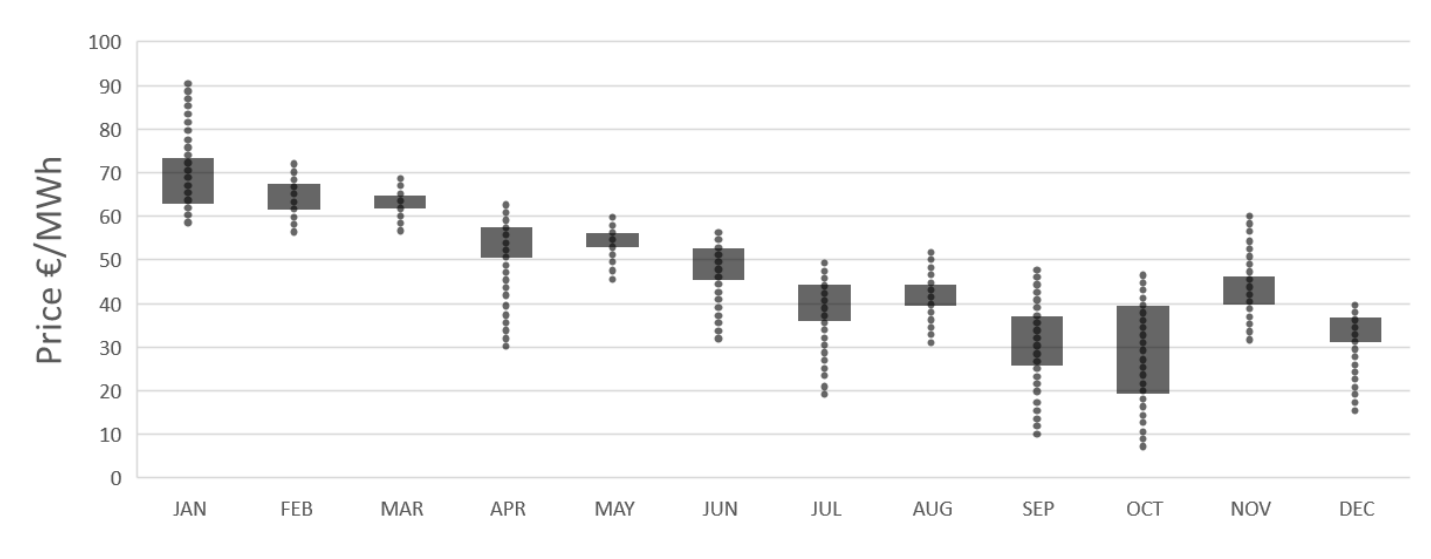

Fig. 1: Spot market electricity prices for Sweden in year 2011. Boxes include $50 \%$ of the values for each month

\subsection{Sensitivity analysis of electricity tariff}

Since the dynamic (spot) price is a small fraction of the end user price, this study also evaluates the potential of the amplified electricity price deviation that is shown in Figure 2, by investigating to what extent the applied algorithm based on the price forecast is sensitive to the hourly and daily price oscillation. To do that, data from 2011 were amplified by applying a factor of 2 to the deviation from the twenty four hours running average. 


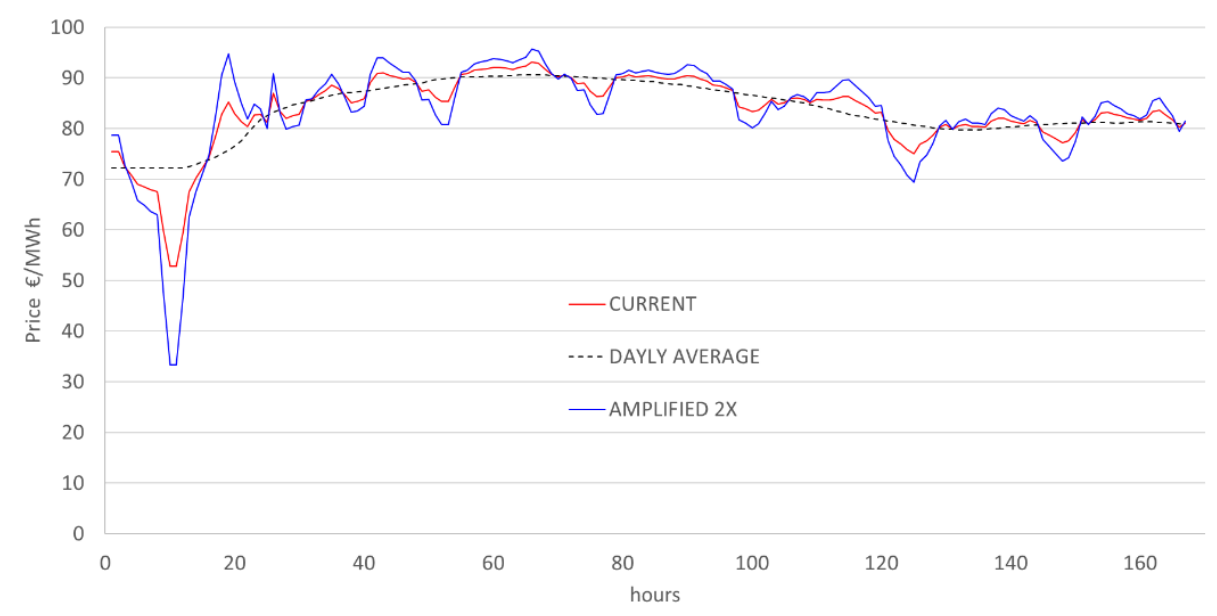

Fig. 2: Amplified electricity price deviation from the $24 \mathrm{~h}$ running average (example of the first week in January 2011)

\subsection{Performance indicators}

The key figures for this study that are used to evaluate the energy and economic performance of the residential PV system are: final energy and self-consumption, annual electricity demand and annual net cost of electricity for the heating system and appliances. A mathematical description of self-consumption can be found in Luthander et al. (2015). If $L(t)$ denotes the instantaneous electric load including appliances, heat pump and auxiliary heater, and $P(t)$ is the instantaneous power from the PV system, the directly consumed PV power $M(t)$ can be defined as:

$M(t)=\min \{L(t), P(t)\}$

if no electric storage is used. When adding battery storage to the system, this can be extended to

$M(t)=\min \{L(t), P(t)+S(t)\}$

where $S(t)<0$ denotes power to storage (charging) and $S(t)>0$ denotes power from storage (discharging). The final energy for the simulation period (FE) is equal to the electric load that cannot be supplied by PV electricity:

$F E=\int_{t_{1}}^{t_{2}} L(t) d t-\int_{t_{1}}^{t_{2}} M(t) d t$

Self-consumption can then be defined as:

$S C=\frac{\int_{t_{1}}^{t_{2}} M(t) d t}{\int_{t_{1}}^{t_{2}} P(t) d t}$

The annual net cost of electricity (NCOE) can be defined as in equation 5 . The cost of the purchased electricity is equal to the added values denoted as fixed fees $C_{\text {fixed }}$ per $\mathrm{kWh}$ and the spot market price $C_{s p}$. The revenue consist of the spot price $C_{s p}$ and the electricity certificates $C_{C}$ :

NCOE $=$ Cost - Income

Cost $=\int\left(C_{s p}+C_{\text {fixed }}\right) P_{\text {from grid }} d t$

Revenue $=\int\left(C_{s p}+C_{C}\right) P_{\text {to grid }} d t$

$P_{\text {from grid }}$ and $P_{\text {to grid }}$ are the power that the system requires from the grid or feed in to the grid, respectively. 


\section{Control strategies with forecast services}

Smart control strategy is beneficial to demand response of the HP system and the optimal utilization of the thermal and electrical storage by the PV electricity production. One control action on the heating system based on electricity prices is to limit the need to purchase of energy when it is expensive. In those periods, if PV production is not sufficient to cover the total energy need, the storage system has a crucial role. In this study the price is defined as high or low by comparing the current price with the average price in a near-future interval of time. That means that the price is considered low or high relatively to what occurs in the hours ahead, and is not related to the average cost over the year. Figure 3 explains the logic that determines whether the current price is low or high.

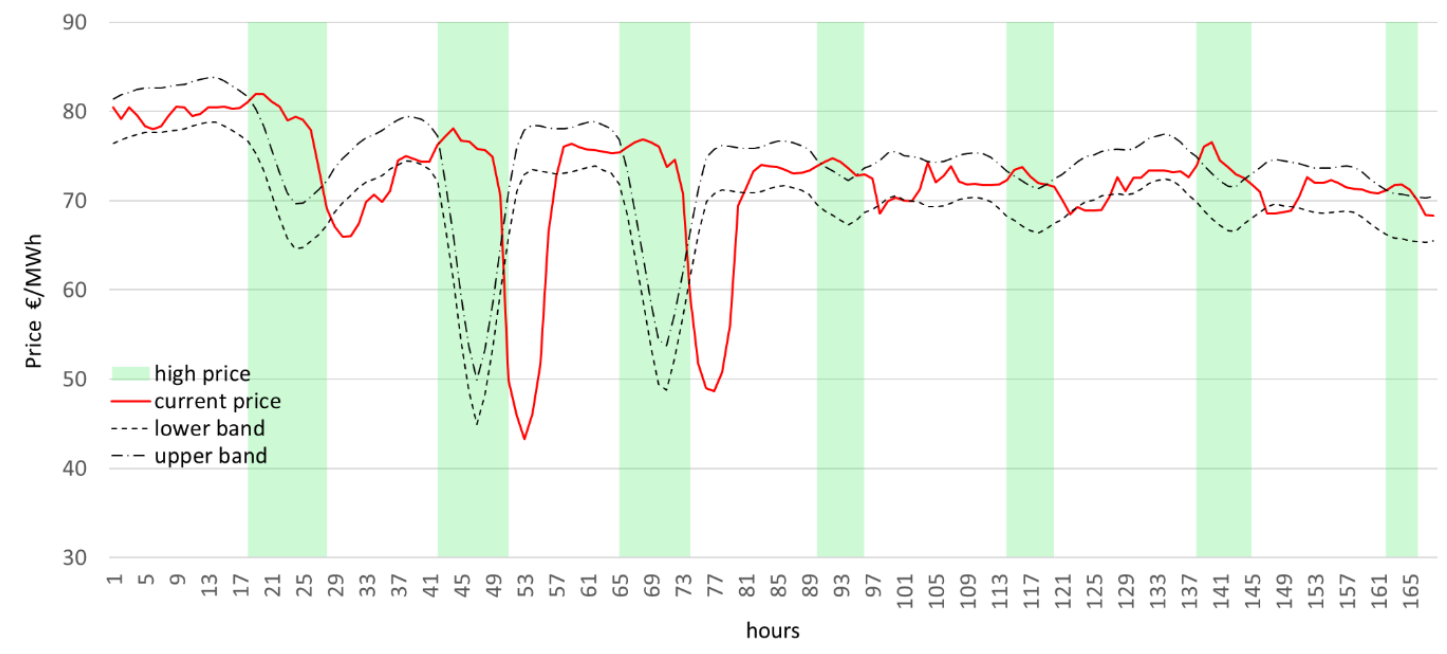

Fig. 3: Example of high price periods (data from a week in January 2011)

In Figure 3, the highlighted intervals are the hours when the price is high, i.e. when the current price is higher than the upper limit. The next day spot market data are obtained by using a perfect forecast, which is derived from the same electricity price data input file shifted one day ahead. The upper and lower limits are obtained by calculating the running average of the near future. The band width is therefore another parameter of this algorithm.

The weather forecast can be used for various applications. In this study the day-ahead global irradiance and the beam component are used as input to the PV model. A perfect forecast is used by shifting the original weather data file one day ahead in order to forecast the PV electricity production. A forecast of space heat demand is not generated or used.

Three algorithms were developed, utilizing either thermal storage by means of the thermal mass of the house (Algorithm 1) or the DHW tank storage, with the electrical storage (Algorithm 2) as well as a combination of using thermal mass storage and the electrical storage (Algorithm 3). The main objective is to control the temperature set points in the room regulators for the space heating using the variable spot market price and the set point in the DHW tank by the day-ahead of PV electricity forecast based on irradiance forecast and a night saving mode. The thermal comfort of the living space (room air temperature) and the availability of DHW were maintained between strict limits. A penalty function for both the SH and the DHW was implemented and monitored for deviations from the base case standards. For the room temperatures a minimum limit was defined as $19.5^{\circ} \mathrm{C}$ in the largest zone of the house and a minimum of $45^{\circ} \mathrm{C}$ in the tap. The penalty functions are based on the guidelines of the IEA SHC Task 32 and based on IEA Task 26 handbook (Weiss 2003). Both strategies are combined with overheating the zones of the house and the DHW tank when excess PV electricity is available. Constraints are also implemented to prevent increasing the cost and to prevent discomfort when the heating demand is high. Constraints of the control decisions that are not listed in the Table 4 are: 
- The auxiliary heater is not allowed to be activated when overheating occurs.

- To prevent discomfort and probably use of auxiliary heater for reheating, it is not allowed to lower the zones' temperature set point when ambient temperature drops below $0{ }^{\circ} \mathrm{C}$ and high price occurs.

- It is not allowed to overheat the zones when the ambient temperature exceeds $10^{\circ} \mathrm{C}$ and low price occurs.

The developed control strategies are described as follows:

- The base case includes the house equipped with a PV system and a heat pump for DHW storage and $\mathrm{SH}$. The HP is controlled solely by the need of SH and the temperature in the DHW storage tank. There is no active use of storage to optimize self-consumption/costs. For a more detailed comparison for the cases with the algorithms that combine both electrical and thermal storage the base case is also simulated with batteries and expressed as ALGb.

- In the first control algorithm (ALG1), the aim is to control the heat pump providing the SH load by the low and high dynamic price and to utilize the excess PV production to reduce net cost and to increase self-consumption. The control is implemented as follows: when high price occurs the room regulators lower the temperature by $0.5 \mathrm{~K}$ whereas the set point temperatures in all the zones are increased by $0.5 \mathrm{~K}$ during periods with low price. ALG1 is implemented with two variations ALG1 and ALG1a.The ALG1a difference includes the amplified dynamic price explained in section 2.5 but with the same control strategy.

- The second control algorithm (ALG2) is applied to the base case system with an additional electrical storage in batteries. The temperature set point of the DHW tank is triggered by the day-ahead weather forecast. The task of the saving function is to limit the cost for charging the DHW tank to the reference value which is compensated later by PV electricity. The time period during which this control is active if from hours 00:00 until hour 06:00. A precondition is that the PV power production between 07:00 and 08:00 exceeds a minimum threshold. Charging of the batteries is controlled by excess PV production to increase self-consumption whereas the HP is controlled solely by the need of SH and temperature in the DHW storage tank.

- The aim of the third control algorithm (ALG3) is to combine the energy storage in the thermal mass of the house, in the DHW tank and in the batteries together with a combination of price forecast and a forecast of the PV power production. The task is to use the batteries to reduce the final energy and to increase self-consumption. The HP is switched on when there is excess PV power production, otherwise it is controlled by the low and high dynamic price signals. The priority is to supply first the electrical loads and then the charging of the battery if there is additional excess PV power.

It should be noted that the battery charging is only allowed during times with excess PV power production after the desired set points in the DHW storage tank have been reached (algorithm 2) or if the SH overheating set point is reached (ALG3). The priority is given to the thermal storage in the course of any day. Table 4 lists the control schemes for on-off control of the HP for the three cases. For ALGb, the main control is that the battery charging is allowed only when excess PV power occurs. 
Tab. 4: Control schemes for on-off control of the HP for the three algorithms

\begin{tabular}{|c|c|c|c|c|}
\hline & & ALG1 & ALG2 & ALG3 \\
\hline Spot price & High price & $\begin{array}{l}\text { Lower set point } \\
0.5 \mathrm{~K} \text { for SH }\end{array}$ & None & $\begin{array}{c}\text { Lower set point } \\
0.5 \mathrm{~K} \text { for } \mathrm{SH}\end{array}$ \\
\hline forecast & Low price & $\begin{array}{c}\text { Increase set point } \\
0.5 \mathrm{~K} \text { for } \mathrm{SH}\end{array}$ & None & $\begin{array}{c}\text { Increase set point } \\
0.5 \mathrm{~K} \text { for } \mathrm{SH}\end{array}$ \\
\hline PV forecast & $\begin{array}{l}\text { Threshold } \\
500 \mathrm{Wh}\end{array}$ & - & $\mathrm{E}_{\mathrm{PV}}>500 \mathrm{Wh}$ & - \\
\hline Night saving & 00:00-06:00 & - & $\begin{array}{l}\text { Lower set point } \\
5 \mathrm{~K} \text { for DHW }\end{array}$ & - \\
\hline $\begin{array}{c}\text { PV excess } \\
P_{P V e}>320 \mathrm{~W}\end{array}$ & $\begin{array}{l}\text { Threshold } \\
\text { 320W }\end{array}$ & $\begin{array}{l}\text { Increase set point } \\
1 \mathrm{~K} \text { for } \mathrm{SH}\end{array}$ & $\begin{array}{l}\text { Increase set point } \\
6 \mathrm{~K} \text { for DHW }\end{array}$ & $\begin{array}{c}\text { Increase setpoint } \\
1 \mathrm{~K} \text { for } \mathrm{SH}\end{array}$ \\
\hline $\begin{array}{c}\text { PV excess } \\
P_{P V e}>0 \mathrm{~W}\end{array}$ & $\begin{array}{l}\text { Threshold } \\
\text { OW }\end{array}$ & - & Battery charging & Battery charging \\
\hline Upper limits & & $\mathrm{T}_{\text {zones }}<23^{\circ} \mathrm{C}$ & $\mathrm{T}_{\text {DHW tank }}<54^{\circ} \mathrm{C}$ & $\mathrm{T}_{\text {zones }}<23^{\circ} \mathrm{C}$ \\
\hline
\end{tabular}

\section{Results}

In this section the results for the key performance indicators, i.e. FE, SC and NCOE, are presented. The developed control strategies are evaluated and compared to the base case with and without batteries. The system was simulated for the base case and each of the algorithms with the three different PV sizes, each with its own battery storage size chosen according to the PV capacity $(3.1 \mathrm{~kW}$ PV and $3.6 \mathrm{kWh}$ battery, $5.7 \mathrm{~kW}$ PV and $7.2 \mathrm{kWh}$ battery, $9.3 \mathrm{~kW}$ PV and $10.8 \mathrm{kWh}$ battery). Table 5 shows a summary of the key figures for the base case of 5.7 $\mathrm{kW}$ PV system without any smart control and with the implementation of the three control strategies. ALG1 is implemented with two variations, ALG1 and ALG1a. ALG1a uses the amplified dynamic price and is compared to the base case with the amplified dynamic price. Moreover ALGb refers to the base case with electrical storage and respectively ALG2 and ALG3 are also compared to ALGb.

Tab. 5: Key figures for the $5.7 \mathrm{~kW}$ PV and the three algorithms plus ALG1a (for all cases appliances use $3437 \mathrm{kWh}^{\mathrm{k}} \mathrm{kar}^{-1}$ and the PV array produces $6285 \mathrm{kWh}_{\text {year }}^{-1}$ )

\begin{tabular}{|c|c|c|c|c|c|c|}
\hline & Base case & ALG1 & ALG1a & ALGb & ALG2 & ALG3 \\
\hline Space heat $\left[\mathrm{kWh}\right.$ year $\left.^{-1}\right]$ & 14046 & 14385 & 14373 & 14050 & 14152 & 14382 \\
\hline DHW $\left[\mathrm{kWh}\right.$ year $\left.^{-1}\right]$ & 3657 & 3653 & 3652 & 3658 & 3711 & 3653 \\
\hline $\begin{array}{c}\text { Heat pump electricity } \\
{\left[\mathrm{kWh}_{\text {year }}{ }^{-1}\right]}\end{array}$ & 5932 & 6242 & 6695 & 5937 & 6375 & 6620 \\
\hline $\begin{array}{c}\text { Aux heater electricity } \\
{\left[\mathrm{kWh}^{-1} \text { year }^{-1}\right]}\end{array}$ & 1568 & 1267 & 990 & 1595 & 1546 & 1101 \\
\hline PV self-consumption [\%] & 31 & 35 & 42 & 47 & 57 & 60 \\
\hline Final energy $\left[\mathrm{kWh}\right.$ year-1 $\left.^{-1}\right]$ & 8994 & 8710 & 8467 & 8080 & 7728 & 7364 \\
\hline NCOE [Euros] & 958 & 947 & 934 & 909 & 920 & 883 \\
\hline
\end{tabular}




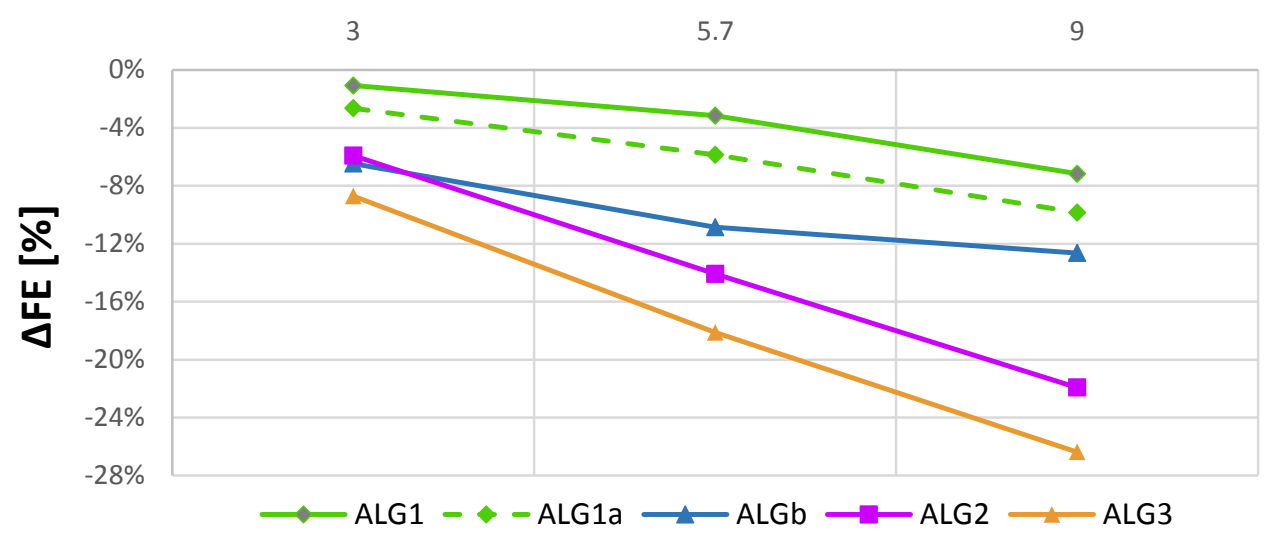

Fig. 4: Comparison of the change in final energy between the base case and the control algorithms ALG1, 2 and 3. ALG1a is shown with the dashed line and refers to the case with the amplified dynamic spot market price and ALG1b refers to the base case with batteries.

Figures 4, 5 and 6 compare the changes between base case and the three algorithms for the three key figures of final energy $(\Delta \mathrm{FE})$, net cost of energy $(\triangle \mathrm{NCOE})$ and self-consumption $(\Delta \mathrm{SC})$ respectively. All algorithms give greater cost and final energy savings the greater the PV system that is installed. ALGb, 2 and 3 including the electrical storage give higher savings in final energy as well as net costs than ALG1, which only uses thermal storage. ALG3 gives the highest reduction in final energy, saving 828, 1630 and $2278 \mathrm{kWh}$ compared to the base case for the 3.1, 5.7 and 9.3 $\mathrm{kW}$ PV sizes respectively. Compared to ALGb the savings are 213, 654 and 1186 $\mathrm{kWh}$ respectively.

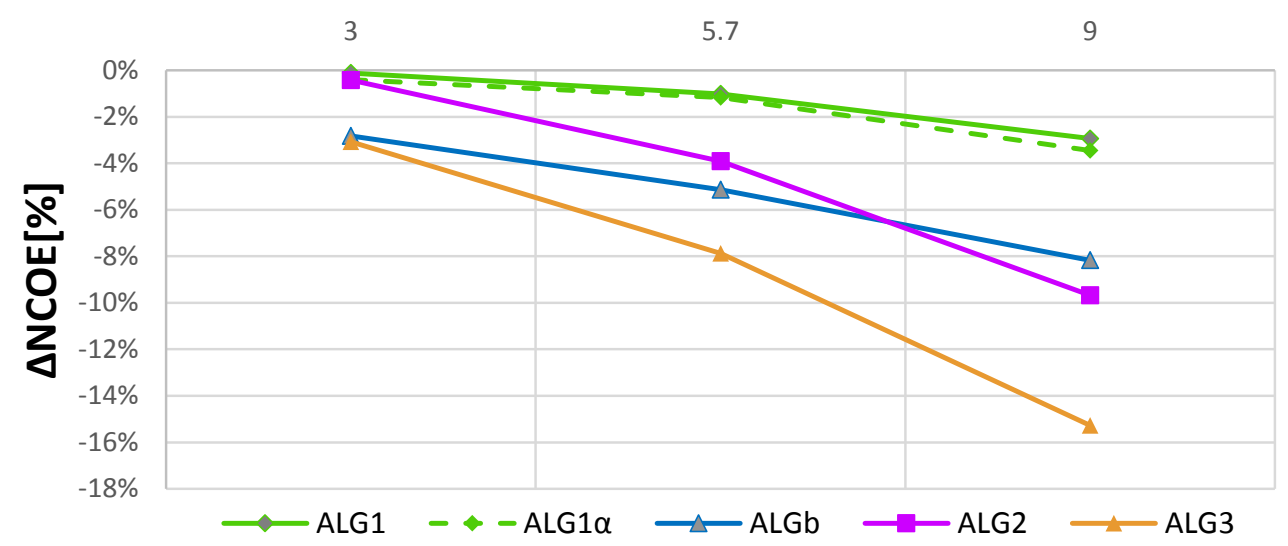

Fig. 5: Comparison of the Annual cost of electricity of the household between the base case and the control algorithms ALG1, 2 and 3. The electrical load for the household appliances is considered constant. ALG1a refers to the case with the amplified dynamic spot market price and ALG1b refers to the base case with batteries.

ALG1 gives gives small net cost savings even with the amplified dynamic price variation (ALG1a), while savings in final energy are larger as are the differences between ALG1 and ALG1a. The net cost savings for ALG3 is 36, 75 and 108 Euros for the small, medium and large PV systems respectively. The NCOE for the two variations of the ALG1 shows no difference even if the SC and final energy show benefits. It is also shown in Figure 5 that ALG2 gives higher cost savings than the base case with batteries, ALGb, only for the largest PV size whereas ALG3 has highest cost savings for all sizes. 


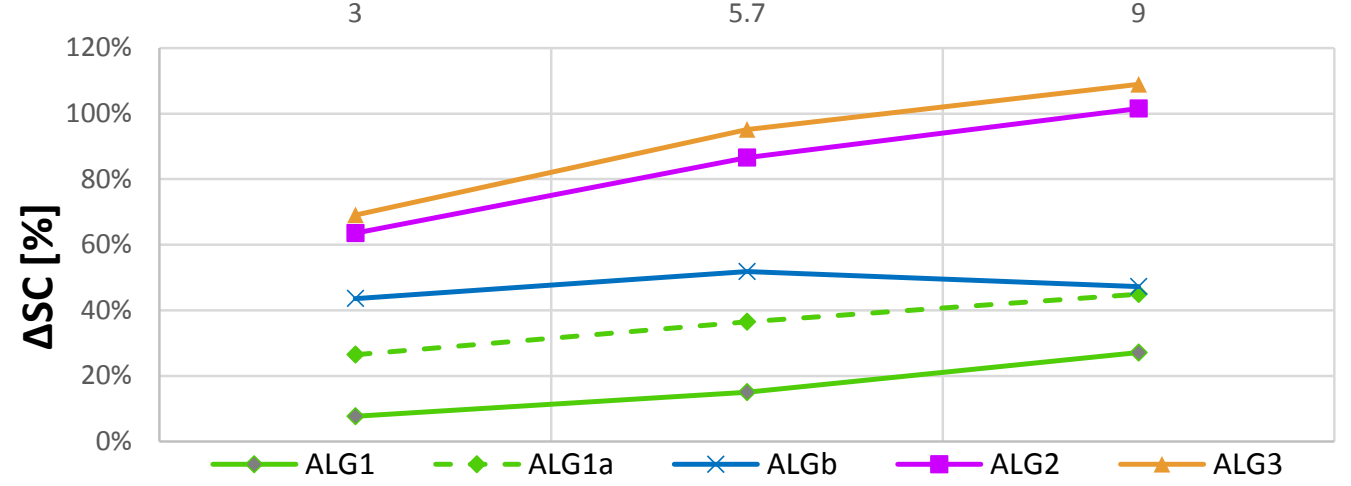

Fig. 6: Comparison of the increase of self-consumed electricity between the base case and the control algorithms ALG1, 2 and 3. Alg1a refers to the case with the amplified dynamic price and ALG1b refers to the base case with batteries.

ALG2 and 3 give twice as large an increase in self- consumption for the system with $9.3 \mathrm{~kW}$ PV compared to the base case. It should be pointed also that for the case of the ALG1a the increase in self-consumption is also more than twice as large between the ALG1 and ALG1a. In terms of absolute values the self-consumption for the medium system is $35.6 \%$ up to $60.4 \%$, while the highest occur for the smallest size system and is $74.7 \%$. Analyzing the results of the two scenarios of the electricity tariff for the base case, the comparison between the base case with the amplified dynamic price and ALG1a, it is found that the net cost is not affected by the amplified dynamic prices. Even if the cost is decreasing the revenue's decrease in this case results in a near zero change in the net cost. Table 6 lists the costs and revenues of the comparison of the base case and ALG1 and ALG1a while Table 7 lists the costs and revenue using ALG2 and ALG3 compared to ALGb. Both tables also give the average annual tariffs for buying and selling electricity. The tariff for buying is nearly double that for selling and does not vary with the algorithm, while that for selling varies slightly due to the different times of selling resulting from different algorithms.

Tab. 6: Cost and revenue and average tariffsfor base case and ALG1 and ALG1a

\begin{tabular}{ccc}
\hline & Base case & ALG1 \\
\hline Cost (tariff) & $1225 €(0.136 € / \mathrm{kWh})$ & $1184 €(0.136 € / \mathrm{kWh})$ \\
\hline Revenue (feed-in tariff) & $267 €(0.065 € / \mathrm{kWh})$ & $237 €(0.064 € / \mathrm{kWh})$ \\
\hline & Base case Amplified & ALG1a \\
\hline Cost (tariff) & $1223 €(0.136 € / \mathrm{kWh})$ & $1154 €(0.136 € / \mathrm{kWh})$ \\
\hline Revenue (feed-in tariff) & $259 €(0.068 € / \mathrm{kWh})$ & $220 €(0.067 € / \mathrm{kWh})$ \\
\hline
\end{tabular}

Tab. 7: Cost and revenue and average tariffs for the base case with batteries ALG1b compared to ALG2 and ALG3

\begin{tabular}{cccc}
\hline & ALGb & ALG2 & ALG3 \\
\hline Cost (tariff) & $1098 €(0.137 € / \mathrm{kWh})$ & $1058 €(0.137 € / \mathrm{kWh})$ & $1007 €(0.137 € / \mathrm{kWh})$ \\
\hline Revenue (feed-in tariff) & $188 €(0.066 € / \mathrm{kWh})$ & $137 €(0.066 € / \mathrm{kWh})$ & $124 €(0.065 € / \mathrm{kWh})$ \\
\hline
\end{tabular}

\section{Discussion}

The inclusion of forecast services in the control decisions increases the complexity of the rule-based decision. 
In the current scenario in Sweden, there is a subsidy for feeding in excess electricity to the grid in order to motivate households to become micro producers and prosumers. With the feed-in subsidy, the revenue of selling electricity is very close to the savings from self-consuming the electricity. Increasing the self-consumption would, therefore, have a minor effect on the total costs. It is, however, not decided how long this subsidy will last, which makes it important to study ways to increase the revenue when the subsidy does not exist anymore. The chosen scenario of this study is therefore one where there is not feed-in subsidy and thus a large difference in tariffs for buying and selling, nearly a factor two. From the evaluation of the economic performance, it can be seen that the revenues of the excess electricity fed into the grid have an impact on the annual cost. Especially when cost saving decisions are implemented, there the cost reduction is partly cancelled out by the the reduction of the revenues, which limits the reduction in net annual costs. The limitation of rule-based algorithms for solving the multi-objective control tasks derives from the need to adjust the control decision seasonally and to develop logical solutions with constraints and priorities that are predefined and not updated throughout the course of the year.

One other point to be considered in the evaluation of the results is the use of a perfect forecast both for the weather forecast and also for the dynamic price. Using a real weather forecast, which includes uncertainties, the actual savings and benefits will be even lower than the ones from this study. In Sweden, the price for the coming 24 hours is decided at noon, and a perfect forecast is thus available.

\section{Conclusion}

This study shows the benefits of smart control using weather and electricity forecast services for decreasing annual net cost of electricity and final energy with the developed algorithms and for increasing the self-consumption. The improvements tend to increase with the larger system sizes. With the largest PV system the annual net cost is decreasing faster for all the algorithms than for the smaller PV systems, with highest cost savings forALG3 (thermal and electrical storage as well as predictive control). For ALG3 and largest PV array the following improvements compared to the base case system (without battery) with same PV array size are achieved: $26 \%$ reduction in final energy; self-consumption is nearly doubled to $60 \%$; and $15 \%$ decrease in net annual cost of electricity. For the same PV size and algorithm, the improvements compared to the base case system with battery are lower, namely: $16 \%$ reduction in final energy; $42 \%$ increase in self-consumption; and $8 \%$ decrease in net annual cost.

Using a battery (ALGb) gives greater savings than using thermal energy storage only (ALG1), for the battery and hot water store sizes used in the study. With the medium-sized PV system of $5.7 \mathrm{~kW}$ ALG1 gives only a small reduction in netannual cost but with electrical storage the reduction in net costs for electricity are 4 to $8 \%$ depending on algorithm used. The final energy can be decreased by $283 \mathrm{kWh}$ (ALG1) up to $1630 \mathrm{kWh}$ (ALG3). With the chosen scenario in this study, the proposed algorithms result in small improvements for cost savings up to $3 \%$ for the smallest system of $3.1 \mathrm{~kW}$ when thermal and electrical storage are combined. Final energy is also reduced for this system by $101 \mathrm{kWh}$ (ALG1) up to $828 \mathrm{kWh}$ (ALG3).

\section{References}

Baetens, R., De Coninck, R., Van Roy, J., Verbruggen, B., Driesen, J., Helsen, L., Saelens, D., 2012. Assessing electrical bottlenecks at feeder level for residential net zero-energy buildings by integrated system simulation. Appl. Energy 96, 74-83. doi:10.1016/j.apenergy.2011.12.098

Bales, C., Betak, J., Broum, M., Chèze, D., Cuvillier, G., Haberl, R., Hafner, B., Haller, M., Hamp, Q., Heinz, A., Hengel, F., Kruck, A., Matuska, T., Mojic, I., Petrak, J., Poppi, S., Sedlar, J., Sourek, B., Thissen, B., Weidinger, A., 2015. Optimized solar and heat pump systems, components and dimensioning: MacSheep New Materials and Control for a next generation of compact combined Solar and heat pump systems with boosted energetic and exergetic performance .

Binder, J., Williams, C.O., Kelm, T., 2012. Increasing PV Self-Consumption, Domestic Energy Autonomy and Grid Compatibility of PV Systems Using Heat-Pumps, Thermal Storage and Battery Storage. 27th Eur. Photovolt. Sol. Energy Conf. Exhib. 4030-4034. doi:10.4229/27THEUPVSEC2012-5AV.1.55 
Fischer, D., et al. 2016. "Impact of PV and variable prices on optimal system sizing for heat pumps and thermal storage." Energy Build. 128: 723-733. doi:10.1016/j.enbuild.2016.07.008

Fischer, D., Madani, H., 2017. "On heat pumps in smart grids: A review." Renew. Sustain. Energy Rev. 70: 342357. doi: 10.1016/j.rser.2016.11.182

Heier, J., Bales, C., Martin, V., 2015. Combining thermal energy storage with buildings - a review. Renew. Sustain. Energy Rev. 42, 1305-1325. doi:10.1016/j.rser.2014.11.031

Heimrath, R., Haller, M., 2007. The Reference Heating System, the Template Solar System of Task 32 [WWW Document]. URL http://archive.iea-shc.org/publications/downloads/task32Reference_Heating_System.pdf (accessed 3.30.16).

Hesaraki, A., Holmberg, S., 2013. An investigation of energy efficient and sustainable heating systems for buildings: Combining photovoltaics with heat pump, in: Smart Innovation, Systems and Technologies. pp. 189-197. doi:10.1007/978-3-642-36645-1_18

Hirvonen, J., Kayo, G., Hasan, A., Sirén, K., 2016. Zero energy level and economic potential of small-scale building-integrated PV with different heating systems in Nordic conditions. Appl. Energy 167, 255-269. doi:10.1016/j.apenergy.2015.12.037

Luthander, R., Widén, J., Nilsson, D., Palm, J., 2015. Photovoltaic self-consumption in buildings: A review. Appl. Energy 142, 80-94. doi:10.1016/j.apenergy.2014.12.028

Nord Pool, 2016. Historical Market Data [WWW Document]. URL http://nordpoolspot.com/historical-marketdata/ (accessed 3.15.16).

Pérez-Lombard, L., Ortiz, J., Pout, C., 2008. A review on buildings energy consumption information. Energy Build. 40, 394-398. doi:10.1016/j.enbuild.2007.03.007

Persson, T., Heier, J., 2010. Småhusens framtida utformning : Hur påverkar Boverkets nya byggregler? [How do the new Swedish building codes affect detached houses of the future?]. Region Gävleborg, Sweden.

Psimopoulos, E., Bales, C., Leppin, L., Luthander, R. (2016) Control Algorithms for PV and Heat Pump System Utilizing Thermal and Electrical Storage, 11th ISES EuroSun 2016

Salpakari, J., Lund, P., 2016. "Optimal and rule-based control strategies for energy flexibility in buildings with PV." Appl. Energy 161: 425-436. doi: 10.1016/j.apenergy.2015.10.036

Thygesen, R., Karlsson, B., 2014. Simulation and analysis of a solar assisted heat pump system with two different storage types for high levels of PV electricity self-consumption. Sol. Energy 103, 19-27. doi:10.1016/j.solener.2014.02.013

Thygesen, R. and B. Karlsson 2016. "Simulation of a proposed novel weather forecast control for ground source heat pumps as a mean to evaluate the feasibility of forecast controls' influence on the photovoltaic electricity self-consumption." Appl. Energy 164: 579-589 Thygesen, R., Karlsson, B., 2016

Weiss W., Solar Heating Systems for Houses - A Design Handbook for SolarCombisystems, Solar Heating and Cooling Executive Committee of theInternational Energy Agency (IEA), James \& James, London, 2003

Widén, J., 2014. Improved photovoltaic self-consumption with appliance scheduling in 200 single-family buildings. Appl. Energy 126, 199-212. doi:10.1016/j.apenergy.2014.04.008

Widén, J., Lundh, M., Vassileva, I., Dahlquist, E., Ellegård, K., Wäckelgård, E., 2009. Constructing load profiles for household electricity and hot water from time-use data - Modelling approach and validation. Energy Build. 41, 753-768. doi: 10.1016/j.enbuild.2009.02.013

Widén, J., Molin, A., Ellegård, K., 2012. Models of domestic occupancy, activities and energy use based on time-use data : deterministic and stochastic approaches with application to various building-related simulations. J. Build. Perform. Simulation, Taylor Fr. 5, 27-44. 